4.-New Meteontes.

WR. GEORGE P. MERRILC in the Proceedings of the United States National Museum describes two new meteorites. The one (rol. li, pp. 525-6) is interesting because it was dredged up from Lake Okechobee, Florida, by a fishing net, and may possibly be a fragment of a meteorite which fell in that region about thirteen years ago. The stone is still firm and shows the characteristic crust. Under the microscope the chondritic nature of the stone is at once evident. Altogether the various fragments secured amount to about 1,100 grams. The other meteorite (vol. lii, pp. 419-22) consists of three fairly complete individuals and a fragment, and weighed altogether 7,605 grams. It is of the usual chondritic type, but the finer details of the structure are obscured by oxidation. It was found near Plainview, Hale County, Texas.

\title{
OBITUAEY
}

\section{ALFRED NICHOLSON LEEDS, F.G.S.}

BORN MIARCH 9, 1847.

DIED AugCST 25, 1917.

(WITH A PORTRAIT, PLATE XXXI.)

WE regret to.have to record the death of $\mathrm{Mr}$. Alfred $\mathrm{N}$. Leeds, one of the most successful pioneers in the modern methods of collecting and preserving fossil vertebrate skeletons. For nearly half a century he had deroted his leisure to recovering the remains of fossil reptiles and fishes from the brickfields in the Oxford Clay near Peterborough ; and the thoroughly scientific and painstaking nature of his work can be appreciated at once by a glance at the unique series of specimens which he contributed to the Geological Department of the British Museum (Yatural History).

The second son of Jir. Edward Thurlow Leeds, of Erebury, Peterborough, Alfred Leeds was born in his ancestral home serenty rears ago. He was educated at the Warwick Grammar School, and afterwards desired to follow a medical career; but circumstances necessitated his assuming the management of the Eyebury farm, and from 1868 onwards this was his daily occupation. His elder brother, Mr. Charles E. Leeds, who was then studying at Oxford, received encouragement from Professor John Phillips to persevere in the collection of fossils round his home which he had already begun. A large part of a Plesiosaurian skeleton which he had discovered was, indeed, described by Phillips in his Geology of Oxford and the Thames Valley (1871). Under such stimulus he was soon joined by Alfred Leeds, and the two brothers gradually perfected methods of extracting the skeletons from the soft clay which were more scientific and thorough than had ever been attempted before. By liberal rewards they induced the workmen not to dig up bones themselres, but to send notice of each discovery to Eyebury. One or both the brothers would then disinter the specimens with their own hands, noting the mode of occurrence of every fragment and clearly distinguishing the 
GEOL. MaG., 1917.

Plate XXNT.

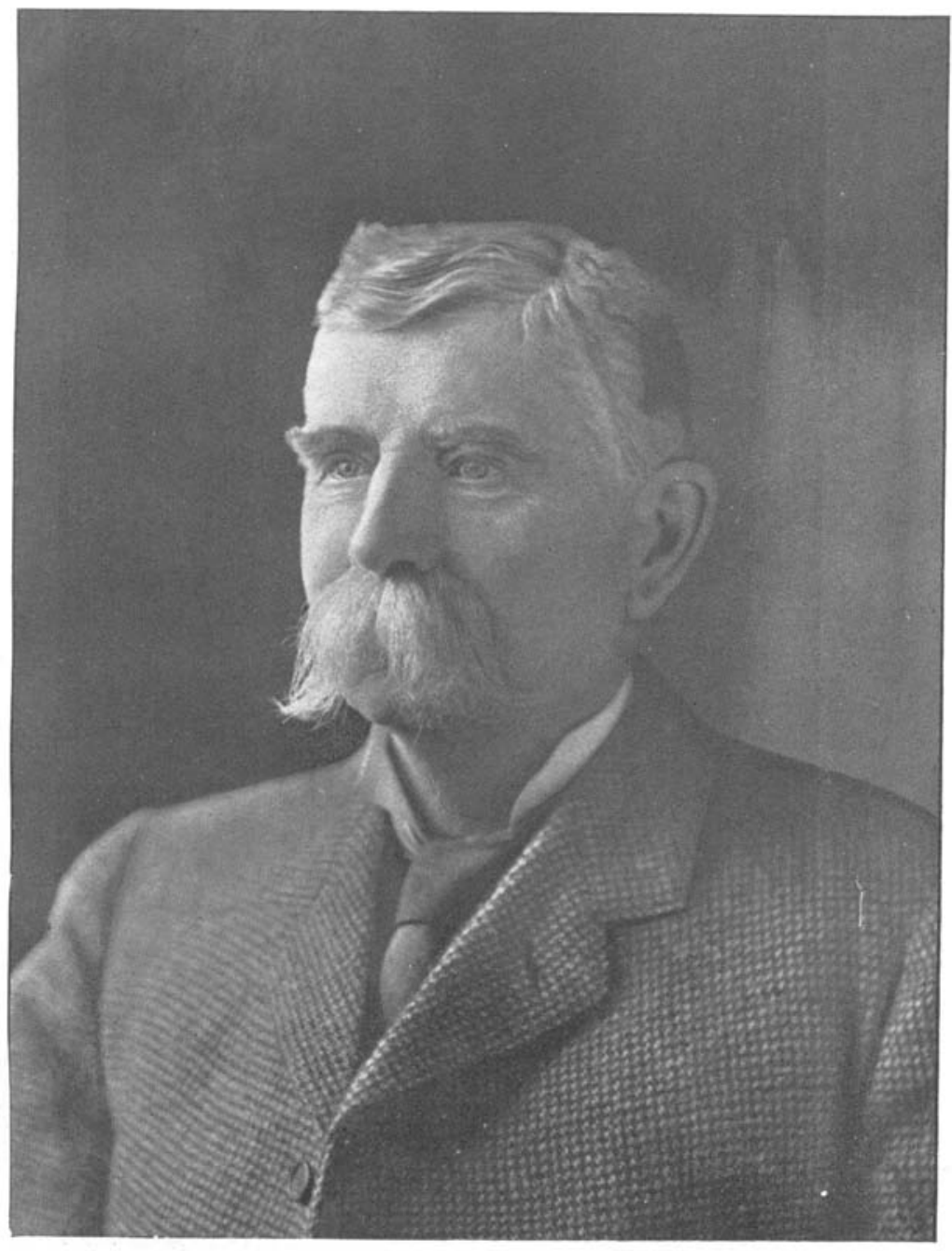

Photo, Lafayette.

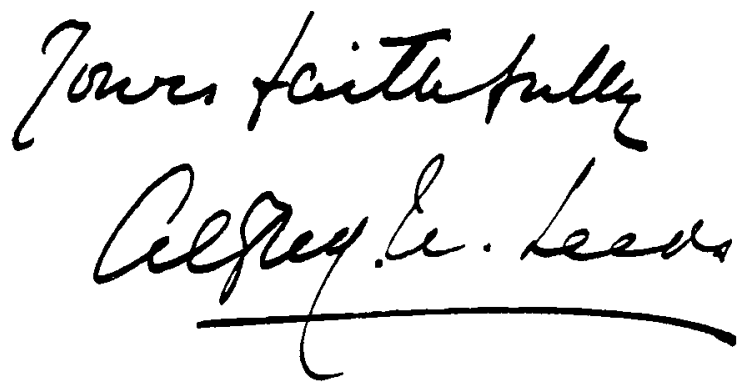

https://doi.org/10.1017/S0016756800136507 Published online by Cambridge University Press 
parts of each individual skeleton. Next they cleaned, washed, and pieced together the broken fragments at home; and they kept such exact records that if any parts proved to be missing they were able to return to the place of discovery and rery often supply the deficiencies. Some of the larger skeletons, in fact, were so widely scattered that they could only be recovered bit by bit in the course of weeks or months as the clay was worked; but the brothers' records were so well kept that even in these difficult cases the missing parts of most remarkable specimens were eventually obtained.

In 1887 Charles Leeds emigrated to New Zealand, where he died in 1912 (see Geol. Mag., Dee. V, Vol. IX, p. 287). For the last thirty years, therefore, Alfred Leeds worked alone, aided only in the delicate processes of preparing specimens by his accomplished wife and by one of his sons, $\mathrm{E}$. Thurlow Leeds, now of the Ashmolean II useum, Oxford. The scientific ralue of his results was acknowledged by the Council of the Geological Society in 1893, when they awarded to him part of the Lyell Fund.

Although Mr. Alfred Leeds never rentured himself to write about his discoveries, he soon became well versed in the osteology of the Mesozoic reptiles and thoroughly appreciated most of the novelties which he met with. He handed over all his material, with his own observations, to rarious specialists who were in friendly communication with him. His collection was thus described by J. W. Hulke, H. G. Seeley, R. Lydekker, C. W. Andrews, and A. S. Woodward, and was also used for reference by $O$. C. Marsh, G. Baur, and others. Among Dinosaurs he obtained important remains of Omosaurus and Stegosaurus, and especially fine portions of the skeleton of Cetiosaurus, including a fragment of the slender whip-shaped end of the tail like that of the American Diplodocus. He was the first to find sufficiently extensive series of Pliosaurus to show the true nature of that gigantic marine reptile. He also discorered two closely related new genera, which were named Peloneustes and Simolestes by Lrdekker and Andrews respectively. His wonderful collection of Plesiosaurians and Ichthyosaurians enabled Seeler to determine for the first time the characters of the pectoral arch of these reptiles; and he discovered several growth-stages in the Plesiosaurians as described by Andrews. Among Crocodilians he obtained a unique series of more or less nearly complete skeletons of Metriorhynchus and Steneosaurus, showing that the former differed from all other known Crocodilians in its complete adaptation to aquatic life, lacking bony scutes, and having the tip of the backbone turned downwards to support a vertical tail-fin as in the Iclithyosaurians. From 1890 onwards all the most inportant of these specimens were gradually acquired by the British Museum, and an exhaustire Descriptive Catalogue of the Marine Reptiles, prepared by Dr. Andrews (with illustrations), was published officially in two volumes in 1910 and 1913.

The fishes discovered by Mr. Leeds were no less important than the reptiles, on account of the manner in which they displayed the separate bones, especially of the head. They include several new species described at different times by Dr. A. S. Woodward. The most striking new genus and species is Leedsia problematica, the 
largest known ganoid fish, probably about 30 feet in length and with a tail (now exhibited in the British Museum) 9 feet in span. Remains of Mesturus add much to our knowledge of the Pycnodont fishes; while the bones of Lepidotus, Caturus, and Hypsocormus can be handled and studied almost as in specially macerated modern skeletons. Among sharks, there is the first proof that the fin-spines named Asteracanthus and the teeth named Strophodus belong to the same fish. Like the reptiles, all the most important fishes are now in the British Museum; but there were enough duplicates of both groups to provide for many other museums, and these are to be found both in this country and in Germany, Austria, and North America.

'Those who had the privilege of Mr. Leeds' friendship will alwars retain happy memories of the hospitality of Mrs. Leeds and himself at Eyebury. He lived in the picturesque fenland farm that was formerly attached to the Abbey of Peterborough, and the thick walls, with a remnant of the moat, were an interesting memento of other days. His musenm occupied the attics of the honse, and the old farm-office was always filled with boxes of the latest discoveries awaiting preparation. Odd trays of specimens in progress were also kept in sight in other rooms to occupy leisure moments. His interests, however, were by no means confined to his fossil bones. He was alive to the progress of science in all ways, and he took an especially active part in local affairs. His loss, indeed, will be mourned by the whole community.

A. S. W.

\section{MISCFIIAINEOUS.}

The Prrocene Cave at Dove Holes. - Early in August last Professor Boyd Dawkins and Dr. Smith Woodward visited the Victory Quarry, Dore Holes, near Buxton, where Pliocene mammalian remains were found in 1902 in a small cave or fissure in the Carboniferous Limestone (Quart. Journ. Geol. Soc, vol. lix, pp. 10529, 1903). Although the fissure in question has long been emptied and destroyed, several similar fissures, filled with clay and sand, are still to be seen; but no fossils appear to have been met with in these deposits during the past fifteen years. The foreman and some other workmen who helped to find the teeth and bones described by Professor Boyd Dawkins are still employed in the quarry, and hare received every inducement to be watchful for similar discoveries.

Piltdown.-During the past summer Dr. Smith Woodward has spent six weeks, partly in association with Professor Elliot Smith and Major Cromer Ashburnham, in exploring the Piltdown grarel. Large excarations were made round the edge of the original pit in which the remains of Piltdown man were found, and much undisturbed gravel was sifted and carefully examined. Nothing, however, was discovered except one unimportant fragment of the tibia of a deer. The second locality in which the late Mr. Charles Dawson picked up fragments of a Piltdowu skull has not yet been identified with certainty, but hopeful inquiries are still being made. 